\title{
Hepatocellular carcinoma in elderly patients: a concise review on systemic therapy with sorafenib
}

\author{
Lombardi Giuseppe ${ }^{1}$, Vitale Alessandro ${ }^{2}$, Sara Lonardi ${ }^{1}$, Bellu Luisa ${ }^{1}$, Pambuku Ardi ${ }^{1}$, \\ Marsico Valentina ${ }^{1}$, Crivellari Gino ${ }^{1}$, Aliberti Camillo ${ }^{3}$, Cillo Umberto ${ }^{2}$, Zagonel Vittorina ${ }^{1}$ \\ ${ }^{1}$ Department of Clinical and Experimental Oncology, Medical Oncology 1, Veneto Institute of Oncology-IRCCS, 35128 Padua, Italy \\ ${ }^{2}$ Department of Surgery, Oncology and Gastroenterology, University of Padua, 35122 Padua, Italy \\ ${ }^{3}$ Interventional Oncology Unit, Veneto Institute of Oncology-IRCCS, 35128 Padua, Italy
}

\begin{abstract}
The treatment of hepatocellular carcinoma (HCC) in elderly patients is unclear. In particular, the efficacy and safety of sorafenib as a systemic treatment in these patients is still under debate. We performed a concise review of sorafenib therapy in this population. However, it is important to make any decisions on treatment for elderly patients with HCC through a multidisciplinary team that includes experts in the liver disease. Patients with good clinical conditions should be treated with sorafenib.
\end{abstract}

Key words: Hepatocellular carcinoma; sorafenib; treatment; chemotherapy; elderly patients

\section{Address for correspondence:}

Dr. Lombardi Giuseppe, Department of Clinical and Experimental Oncology, Medical Oncology 1, Veneto Institute of Oncology-IRCSS Via Gattamelata, 64, 35128 Padua, Italy. E-mail: giuseppe.lombardi@ioveneto.it

Received: 17-02-2015, Accepted: 11-05-2015

\section{INTRODUCTION}

Hepatocellular carcinoma (HCC) is the fifth most common solid organ malignancy worldwide and the second cause of cancer-related mortality, ${ }^{[1]}$ with the highest incidence rates in areas where hepatitis B virus infection is endemic such as South-East Asia and sub-Saharan Africa. ${ }^{[2]}$ Similar to other common cancers, the incidence of HCC increases in relation to age. In Western countries, it tends to peak at the age of 75 years and in the United States it rarely occurs before the age of 40 years. In Chinese and in black African populations it generally occurs in younger patients. ${ }^{[2]}$

Well-known risk factors typically characterize the development of HCC. The most frequent conditions include chronic viral hepatitis (types $\mathrm{B}$ and $\mathrm{C}),{ }^{[3]}$ alcohol intake, and aflatoxin

\begin{tabular}{|l|c|}
\hline \multicolumn{2}{|c|}{ Access this article online } \\
\hline \multirow{2}{*}{ Website: } & Quick Response Code \\
\cline { 2 - 2 } http://www.hrjournal.net/ & \\
\hline & DOI: \\
10.4103/2394-5079.157695 & \\
&
\end{tabular}

exposure. ${ }^{[4]}$ Cirrhosis is another important risk factor, which may be triggered by chronic viral hepatitis, alcohol or inherited metabolic diseases. Therefore, in up to $90 \%$ of cases, HCC becomes progressively worse on account of underlying liver diseases so that in most patients, prognosis and management are influenced by the presence of two separate entities: Chronic hepatitis with or without cirrhosis and HCC. ${ }^{[3,5,6]}$ Consequently, the choice of the appropriate HCC therapy should consider the limitations presented by underlying liver diseases.

In the most recent HCC guidelines (EASL/EORTC, AASLD, AISF, AIOM), disease staging includes tumor characteristics, underlying liver cirrhosis, and performance status. Treatment allocation is then based on these parameters. Patient age is not taken into account though there is an increasing focus on elderly patients. Due to the aging of the population, this group represents the fastest growing segment of populations with cancer.

The aim of this investigation was to review all the gathered experience of using sorafenib, a targeted multikinase inhibitor, in the treatment of HCC, with a focus on the evaluation of safety and the efficacy of this agent in the elderly as compared to younger patients. 


\section{DEFINITION OF “ELDERLY PATIENT”}

Due to the fact that aging involves a progressive shortening of life expectancy and reduction in the functionality of organ systems, the definition of an "elderly patient" is somewhat hazy and still a matter of debate. ${ }^{[7]}$ What is the upper limit of age in which a patient is considered as old? Should the cut-off of 70 years used in clinical studies and in current clinical practice to be considered an acceptable and reasonable boundary? Is age the only parameter to take into account for defining an elderly patient or should the so-called stage of aging be evaluated more extensively? It has been demonstrated that the standardized geriatric evaluation systems, assessing additional parameters such as comorbidities, cognitive, and health status, may better correlate with therapy toxicity and patient outcomes, ${ }^{[8}$ and could subsequently supply additional information to the standard performance status scale, such as KPS or ECOG PS, normally used in oncology. However, there has yet to be a general consensus on what the best geriatric evaluation system to use is.

Due to their fragile conditions, elderly patients are generally perceived to be more susceptible to the toxic effects of cancer therapy and, as a result, gain less clinical benefits from treatments due to frequent dose interruptions or permanent discontinuations of the drug. This perception could be related to the fact that this population is underrepresented in clinical trials, which are often conducted excluding patients exceeding a certain age limit or those bearing comorbidities.

However, a growing body of evidence suggests that older patients with adequate organ function and a reasonable life expectancy should receive the same treatment as younger patients. A retrospective analysis is evaluating 13 different molecularly targeted cancer therapies found similar frequencies of drug-related adverse events among the elderly as in younger patients. ${ }^{[9]}$ To limit this gap and identify the most appropriate treatment of elderly patients, it is advisable to assess how available treatment options behave in the framework of both well-conducted clinical trials and in everyday clinical practice.

\section{TREATMENT WITH SORAFENIB}

Therapeutic options for HCC range from surgeries (resection or liver transplantation) to loco-regional therapies (percutaneous ethanol injection, radiofrequency ablation or trans-arterial chemo-embolization) and systemic treatment, depending either on the stage of tumor disease or on the underlying liver disease. Currently, treatment with sorafenib has been recognized as the only standard systemic therapy for HCC. It is indicated for patients with well-preserved liver function (Child-Pugh A class) and with advanced tumors or for those with tumor progressing upon loco-regional therapies. ${ }^{\mid 10]}$

The efficacy of sorafenib in HCC was established in SHARP ${ }^{[1]}$ and Asian-Pacific, ${ }^{[12]}$ two randomized, phase III multicenter, double-blind, placebo-controlled trials that led to the approval of drug by the International Health Authorities. In both studies, sorafenib administered at the dose of $400 \mathrm{mg}$ twice daily demonstrated a statistically significant improvement of overall survival and time to progression than compared to the placebo in patients with well-preserved liver function (Child-Pugh A). Sorafenib proved to be well-tolerated, with skin toxicity (hand-foot skin reaction), diarrhea, and asthenia representing the most common adverse effects. Temporary treatment interruptions and/or dose reductions along with immediate specific treatment of adverse events proved effective in managing adverse drug effects.

In the SHARP trial, the median age of patients treated with sorafenib was $64.9 \pm 11.2$ years, whereas the Asia-Pacific trial was 51 years (range 23-86). In both studies, the inclusion criteria did not set an upper age limit. The Asia-Pacific study included younger patients on account of the earlier onset of HCC in those regions. The preplanned subgroup analysis according to the patients' age grouping in the Asia-Pacific study showed that sorafenib provided similar clinical benefits in both younger $(<65$ years) and older $(\geq 65$ years) patients. Following the two registrative trials, the use of sorafenib has also been evaluated in large patient populations treated according to everyday clinical practice.

Global Investigation of therapeutic DEcisions in HCC and Of its treatment with sorafeNib, is an international, post-approval, prospective, non-interventional study undertaken to evaluate the safety and the efficacy of sorafenib in patients with unresectable HCC, in which the inclusion criteria of patients closely corresponded to that of real-life practices. ${ }^{[13]}$ This study carried out in 39 countries worldwide, enrolled 3,371 patients; of these, 3,202 were available for the evaluation of safety. Two interim analyses (after the accrual of 500 and 1,500 patients, respectively) and the final analysis confirmed the safety profile of sorafenib previously recorded in the phase III pivotal trials, without detecting any new unexpected adverse events. A breakdown of the safety of sorafenib according to age groups was available only for the second interim analysis (1,571 patients) ${ }^{\left[{ }^{[13]}\right.}$ The comparison of sorafenib safety profiles in younger $(<65$ years, $n=883$ ) and older patients ( $\geq 65$ years, $n=688$ ) showed that the incidence of adverse events, drug-related adverse events, and serious adverse events was independent of age, similar in both older and younger patients. It is interesting to 
note that even the adverse events resulting in permanent discontinuation of the drug were similar in both groups. ${ }^{[13]}$

The impact of age on the effects of sorafenib in clinical practice was also examined in different single and multicenter experiences $^{[14-20]}$ and discussed in a few reviews. ${ }^{[21,22]} \mathrm{A}$ table summarizing the efficacy and the safety of older and younger patients treated with sorafenib reported in most papers so far published are reported [Table 1].
The first non-Asian study investigating the use of sorafenib in a large cohort of elderly patients was published in 2013. Di Costanzo et al. ${ }^{[14]}$ analyzed a cohort of consecutive patients not eligible for surgery or loco-regional treatment, with Child-Pugh score $\leq 7$, treated with sorafenib. Clinical outcomes and treatment-related adverse events were compared between younger ( $<70$ years) and older ( $\geq 70$ years) patients. Overall, 150 patients (90 in the younger and 60 in the older group) were evaluated. The study

Table 1: Synoptic table outlining the results in younger and older patients with HCC treated with sorafenib

\begin{tabular}{lll}
\hline Authors & Study design & Efficacy \\
\hline Cheng et al. ${ }^{[12]}$ & $\begin{array}{l}\text { Open, randomized, } \\
\text { preplanned subgroup }\end{array}$ & Similar efficacy between $<65$ years \\
& $\begin{array}{l}\text { exploratory analysis } \\
\text { Lencioni et } a l .{ }^{[13]}\end{array}$ & Open
\end{tabular}

Safety

Lencioni et al. ${ }^{[13]} \quad$ Open

Safety of sorafenib according to age groups only for the second interim analysis ( 1,571 patients). Comparison of sorafenib safety profile between younger ( $<65$ years, $n=883$ ) and older patients ( $\geq 65$ years, $n=688$ ) showed that the incidence of adverse events, drug-related adverse events, and serious adverse events was similar in both older and younger patients independently of age

Di Costanzo et al. ${ }^{[14]}$ Open

150 patients

$<70$ years $(n=90)$ : treatment

duration $=4$ months, TTP $=8$ months,

OS $=12$ months

$\geq 70$ years $(n=60)$ : treatment duration

$=4$ months, TTP $=12$ months,

OS $=16$ months

Edeline et al. ${ }^{[15]} \quad$ Retrospective

129 patients

$<70$ years $(n=78)$ : $\mathrm{PFS}=5.6$ months,

OS $=9.6$ months

$\geq 70$ years $(n=51)$ : PFS $=5.6$ months,

OS $=12.6$ months

Jo et al. ${ }^{[16]} \quad$ Retrospective

185 patients

$<80$ years $(n=161):$ OS $=10.5$ months

$\geq 80$ years $(n=24)$ : OS $=11.7$ months

No difference in response rate

Montella et al. ${ }^{[1]} \quad$ Retrospective

60 patients $>60$ years

Disease control rate $=80 \%$, stable

disease $=76.6 \%$, TTP $=7$ months,

OS $=10$ months

Francini and Bianco ${ }^{[18]}$ Retrospective

31 patients, aged between 70 and 83 years
Morimoto et al. ${ }^{[19]} \quad$ Retrospective
Retrospective
76 patients

$<75$ years $(n=52), \geq 75$ years $(n=24)$ Average OS and the median TTP were comparable between two dose regimens 400 bid and $400 \mathrm{qb}$ (5.3 months vs. 5.0 months, $P=0.839)$

172 patients

$\geq 70$ years $(n=35):$ PFS $=2.99$

months, OS $=5.32$ months

$<70$ years $(n=137)$ :

PFS $=3.09$ months, OS $=5.16$ months
Similar between the two groups: occurrence of severe toxicities (41.0\% vs. 51.0\%) and hospitalization due to toxicity (9.0\% vs.

$13.7 \%)$. Asthenia and bleeding more frequent in the elderly

No difference as for frequency and severity of AEs

Thrombosis correlated to TTP. Full doses in 11 out of 60 patients (18.3\%)

AEs were reported in all patients, mostly during the 1st month and of grade 1 or 2 . Grade 3 side effects: fatigue (22.6\%), hand-foot skin reaction (19.3\%), thrombocytopenia (12.9\%), hyperbilirubinemia (9.7\%), abdominal pain (9.7\%), and only in one case, diarrhea (3.2\%). No grade 4 toxicity

Sorafenib has a positive impact on self-sufficiency and quality of life

The median treatment duration and overall incidence of ADRs

were not statistically different with increasing age

Subgroup analysis revealed that treatment discontinuation because of ADRs was more frequent among the $\geq 75$ years

$(41.7 \%)$ than among the $<75$ years $(15.0 \%)$

AEs with a standard dosage of sorafenib: $41.7 \%$ in patients

$\geq 75$ years and $15.0 \%$ in patients $<75$ years. This difference is statistically significant. With half-dose regimen, no difference between the age groups was observed

Grades 3-4 AEs: $\geq 70$ years $(68.6 \%),<70$ years $(62.7 \%)$

nts; OS: overall survival; TTP: time to progression; PFS: progress free survival; ADRs: adverse drug reactions 
showed that in elderly HCC patients with cirrhosis, sorafenib is as safe and effective as in younger patients. No unexpected adverse events related to advanced age were observed. Temporary and permanent sorafenib discontinuations were more frequent in older than in younger patients. However, this difference did not turn out to be statistically significant.

A recently published retrospective study on 129 patients compared the efficacy and safety of sorafenib in HCC patients with different ages ( $\geq 70$ and $<70$ years). ${ }^{[16]}$ The efficacy and the overall safety were found to be similar between the two groups. Asthenia and bleeding were more frequent in older patients as a result of a higher use of platelet aggregation inhibitors in this population.

The efficacy and safety of sorafenib in patients $\geq 80$ years old were examined in a multicenter Japanese retrospective study. ${ }^{[17]}$ One hundred and eighty-five patients were reviewed, 24 of them being $\geq 80$ years old and 161 being $<80$ years old. Median overall survival was greater in older patients (11.7 months) than compared to those $<80$ years old ( 10.5 months), with a good tolerability in both groups.

Many elderly patients are frail. Frailty implies a reduced organ function, the presence of comorbidities and impairment of physical function. ${ }^{[7]}$ Concomitant assumption of different drugs could moreover interfere with sorafenib absorption. However, studies on the use of sorafenib in the elderly suggest overcoming the predisposition to consider older patients associated with poor prognosis and poor tolerance to drugs. In these first experiences, in fact, efficacy and safety of sorafenib do not seem influenced by the age. All elderly patients undergoing sorafenib treatment should be strictly monitored to evaluate physical (blood pressure, vital signs) and laboratory parameters to prevent and promptly manage adverse events. Dose adjustments, in order to alleviate adverse events, may be a successful strategy to avoid permanent discontinuation and maximize the benefit of the drug.

A comprehensive geriatric assessment (CGA) should be performed by geriatricians to evaluate the functional and global health status of these elderly patients because CGA results are closely related to the prognosis of elderly patients in general.

\section{CONCLUSION}

Given the challenges of managing the complexity of HCC often associated with underlying liver disease and the complex health conditions of elderly patients, it is extremely important to make any decisions on treatment through a multidisciplinary team that includes experts in liver disease and in clinical oncology to perform a personal non-protocol approach for the oncological care and management of elderly patients with HCC. However, elderly patients with good clinical conditions should be treated with sorafenib.

\section{REFERENCES}

1. International Agency for Research on Cancer. GLOBOCAN 2012 Cancer Fact Sheets. Available from: http://www.globocan.iarc.fr/Pages/ fact_sheets_cancer.aspx. [Last cited on 2015 Apr 27].

2. El-Serag HB. Hepatocellular carcinoma. NEngl J Med 2011;365:1118-27.

3. Michielsen PP, Francque SM, van Dongen JL. Viral hepatitis and hepatocellular carcinoma. World J Surg Oncol 2005;3:27.

4. Bosch FX, Ribes J, Díaz M, Cléries R. Primary liver cancer: worldwide incidence and trends. Gastroenterology 2004;127:S5-16.

5. Degos F, Christidis C, Ganne-Carrie N, Farmachidi JP, Degott C, Guettier C, Trinchet JC, Beaugrand M, Chevret S. Hepatitis C virus related cirrhosis: time to occurrence to hepatocellular carcinoma and death. Gut 2000;47:131-6.

6. El-Serag HB, Davila JA, Petersen NJ, McGlynn KA. The continuing increase in the incidence of hepatocellular carcinoma in the United States: an update. Ann Intern Med 2003;139:817-23.

7. Yancik R, Ganz PA, Varricchio CG, Conley B. Perspectives on comorbidity and cancer in the older patient: approach to expend the knowledge base. J Clin Oncol 2001;19:1147-51.

8. Dale W, Mohile SG, Eldadah BA, Trimble EL, Schilsky RL, Cohen HJ, Muss HB, Schmader KE, Ferrell B, Extermann M, Nayfield SG, Hurria A; Cancer and Aging Research Group. Biological, clinical, and psychosocial correlates at the interface of cancer and aging research. J Natl Cancer Inst 2012;104:581-9.

9. Townsley CA, Pond GR, Oza AM, Hirte HW, Winquist E, Goss G, Degendorfer P, Moore MJ, Siu LL. Evaluation of adverse events experienced by older patients participating in studies of molecularly targeted agents alone or in combination. Clin Cancer Res 2006;12:2141-9.

10. European Association for the Study of the Liver; European Organisation for Research and Treatment of Cancer. EASL-EORTC clinical practice guidelines: management of hepatocellular carcinoma. J Hepatol 2012;56:908-43.

11. Llovet JM, Ricci S, Mazzaferro V, Hilgard P, Gane E, Blanc JF, de Oliveira AC, Santoro A, Raoul JL, Forner A, Schwartz M, Porta C, Zeuzem S, Bolondi L, Greten TF, Galle PR, Seitz JF, Borbath I, Häussinger D, Giannaris T, Shan M, Moscovici M, Voliotis D, Bruix J; SHARP Investigators Study Group. Sorafenib in advanced hepatocellular carcinoma. N Engl J Med 2008;359:378-90.

12. Cheng AL, Kang YK, Chen Z, Tsao CJ, Qin S, Kim JS, Luo R, Feng J, Ye S, Yang TS, Xu J, Sun Y, Liang H, Liu J, Wang J, Tak WY, Pan H, Burock K, Zou J, Voliotis D, Guan Z. Efficacy and safety of sorafenib in patients in the Asia-Pacific region with advanced hepatocellular carcinoma: a phase III randomized, double-blind, placebo controlled trial. Lancet Oncol 2009;10:25-34.

13. Lencioni R, Kudo M, Ye SL, Bronowicki JP, Chen XP, Dagher L, Furuse J, Geschwind JF, de Guevara LL, Papandreou C, Takayama T, Yoon SK, Nakajima K, Lehr R, Heldner S, Sanyal AJ. GIDEON (Global Investigation of therapeutic DEcisions in hepatocellular carcinoma and Of its treatment with sorafeNib): second interim analysis. Int J Clin Pract 2014;68:609-17.

14. Di Costanzo GG, Tortora R, De Luca M, Galeota Lanza A, Lampasi F, Tartaglione MT, Picciotto FP, Imparato M, Mattera S, Cordone G, Ascione A. Impact of age on toxicity and efficacy of sorafenib-targeted therapy in cirrhotic patients with hepatocellular carcinoma. Med Oncol 2013;30:446. 
15. Edeline J, Crouzet L, Le Sourd S, Larible C, Brunot A, Le Roy F, Cattenoz C, Latournerie M, Gédouin D, Guillygomarc'h A, Boucher E. Sorafenib use in elderly patients with hepatocellular carcinoma: Caution about use of platelet aggregation inhibitors. Cancer Chemother Pharmacol 2015;75:215-9.

16. Jo M, Yasui K, Kirishima T, Shima T, Niimi T, Katayama T, Mori T, Funaki J, Sumida Y, Fujii H, Takami S, Kimura H, Mitsumoto Y, Minami M, Yamaguchi K, Yoshinami N, Mizuno M, Sendo R, Tanaka S, Shintani H, Kagawa K, Okanoue T, Itoh Y. Efficacy and safety of sorafenib in very elderly patients aged 80 years and older with advanced hepatocellular carcinoma. Hepatol Res 2014;44:1329-38.

17. Montella L, Addeo R, Cennamo G, Vincenzi B, Palmieri R, Sperlongano P, Sperlongano R, Iodice P, Russo P, Del Prete S. Sorafenib in elderly patients with advanced hepatocellular carcinoma: a case series. Oncology 2013;84:265-72.

18. Francini E, Bianco V. Tolerability of single-agent sorafenib in the treatment of elderly patients with hepatocellular carcinoma (HCC). Hepatology 2014;60:764-5.

19. Morimoto M, Numata K, Kondo M, Hidaka H, Takada J, Shibuya A, Kobayashi S, Ohkawa S, Okuse C, Morita S, Taguri M, Tanaka K. Higher discontinuation and lower survival rates are likely in elderly Japanese patients with advanced hepatocellular carcinoma receiving sorafenib. Hepatol Res 2011;41:296-302.

20. Wong H, Tang YF, Yao TJ, Chiu J, Leung R, Chan P, Cheung TT, Chan AC, Pang RW, Poon R, Fan ST, Yau T. The outcomes and safety of single-agent sorafenib in the treatment of elderly patients with advanced hepatocellular carcinoma (HCC). Oncologist 2011;16:1721-8.

21. Germano D, Tinessa V, Barletta E, Cannella L, Daniele B. Targeted therapy for advanced hepatocellular cancer in the elderly: focus on sorafenib. Drugs Aging 2013;30:887-92.

22. Cabibbo G, Maida $\mathrm{M}$, Cammà $\mathrm{C}$, Craxì A. Is the efficacy of sorafenib treatment in patients with hepatocellular carcinoma affected by age? Expert Rev Anticancer Ther 2013;13:1355-61.

How to cite this article: Giuseppe L, Alessandro V, Lonardi $S$, Luisa B, Ardi P, Valentina M, Gino C, Camillo A, Umberto C, Vittorina Z. Hepatocellular carcinoma in elderly patients: a concise review on systemic therapy with sorafenib. Hepatoma Res 2015;1:58-62.

Source of Support: Nil. Conflict of Interest: None declared. 